ISSN 1980-5098

\title{
SUBSTÂNCIAS HÚMICAS EM CAMBISSOLO SOB VEGETAÇÃO NATURAL E PLANTIOS DE PINUS EM DIFERENTES IDADES
}

\author{
HUMIC SUBSTANCES ON A HUMIC DYSTRUPEPT UNDER NATIVE GRASSLAND AND \\ PINE PLANTATION ON DIFFERENT AGES
}

\author{
Priscylla Pfleger ${ }^{1}$ Paulo Cezar Cassol ${ }^{2}$ Álvaro Luiz Mafra ${ }^{2}$
}

\begin{abstract}
RESUMO
Devido à grande área ocupada com reflorestamentos de pinus no sul do Brasil, considera-se necessário avaliar o impacto dessa cultura no estoque de carbono orgânico do solo, especialmente com relação às frações das substâncias húmicas (SH). Nesse contexto, o presente trabalho teve como objetivo avaliar as alterações na quantidade e proporção das substâncias húmicas da matéria orgânica em solo representativo do Planalto Catarinense devido à substituição da vegetação natural por povoamentos de Pinus taeda. Foram avaliadas quatro situações de uso em áreas localizadas no município de Ponte Alta, sendo uma de campo natural (CN) e três plantios de Pinus taeda com idades de 5 (P05), 16 (P16) e 21 (P21) anos em segunda rotação, em solo classificado como Cambissolo Húmico distrófico. Amostras de solos compostas por sete sub amostras foram coletadas em sete pontos amostrais dentro de cada área nas camadas de 0-5 cm, 5-10 $\mathrm{cm}, 10-20 \mathrm{~cm}, 20-30 \mathrm{~cm}$ e 30-40 cm de profundidade. Os teores de carbono das SH da matéria orgânica do solo (MOS) foram determinados através de fracionamento químico resultante da solubilização em meios ácido e básico. Os teores e proporções das SH da MOS variaram significativamente em função da situação de uso e profundidade analisados, evidenciando maiores quantidades na camada superficial e seu aumento com a idade do pinus. Em geral, os maiores valores de $\mathrm{C}$ nas frações e camadas avaliadas foram observados no P21 e os menores no P05.
\end{abstract}

Palavras-chave: fracionamento; ácidos húmicos; reflorestamento; sequestro de carbono.

\begin{abstract}
Due to the great area occupied with Pinus sp. plantations in southern Brazil, it is considered necessary to evaluate the impact of this kind of crop on soil organic carbon stock, specially related to fractions from humic substances (HS). On this context, this work aims to evaluate the changes on humic substances quantity and the proportion of organic matter on representative soil of the highlands in Santa Catarina state due to replacement of natural grassland by Pinus taeda stands. Four situations of soil use on areas located in Ponte Alta town were evaluated, being one of natural grasslands $(\mathrm{CN})$ and tree of Pinus taeda forests with 5 (P05), 16 (P16) and 21 (P21) years old on second rotation, on soil classified as Humic Dystrupept. Soil samples composed by seven subsamples were collected on seven points inside every area in the $0-5 \mathrm{~cm}$, $5-10 \mathrm{~cm}, 10-20 \mathrm{~cm}, 20-30 \mathrm{~cm}, 30-40 \mathrm{~cm}$ layers. The carbon contents of HS in the SOM were determined by chemical fractionating resulted from alkaline or acid extraction. The HS contents and proportions varied according to the soil use and depth analyzed, showing more quantity in the surface layer and its increasing with pinus age. In general, the highest levels of $\mathrm{C}$ on fractions and layers evaluated were observed on P21 and the lowest on P05 uses.
\end{abstract}

Keywords: fractionation; humic acids; reforest; carbon sequestration.

1 Engenheira Florestal, Doutoranda do Programa de Pós-Graduação em Ciência do Solo, Universidade do Estado de Santa Catarina, Av. Luiz de Camões, 2090, Bairro Conta Dinheiro, CEP 88520-000, Lages (SC), Brasil. cyllapfleger@hotmail.com

2 Engenheiro Agrônomo, Dr., Professor da Universidade do Estado de Santa Catarina, Av. Luiz de Camões, 2090, Bairro Conta Dinheiro, CEP 88520-000, Lages (SC), Brasil. paulo.cassol@udesc.br / alvaro.mafra@udesc.br

Recebido para publicação em 27/12/2013 e aceito em 18/11/2015

Ci. Fl., v. 27, n. 3, jul.-set., 2017 


\section{INTRODUÇÃO}

Ruddiman (2005) relatou que a cerca de oito mil anos atrás, os humanos iniciaram intervenções na natureza que modificam o clima e as concentrações de gases de efeito estufa na atmosfera. No entanto, mais terras foram convertidas em lavouras desde 1945 do que nos séculos XVIII e XIX juntos, e agora cerca de um quarto $(24 \%)$ da superfície terrestre do planeta foi transformado em sistemas de cultivos.

Novas informações e o conhecimento sobre os recursos florestais são necessários para formular, de forma equilibrada, novas políticas que incidem sobre regiões e biomas do país, influenciando os padrões de uso da terra. No caso do Brasil, a questão merece ainda maior atenção, pois cerca de $60 \%$ de seu extenso território ainda são cobertos por florestas. No entanto, também é fato conhecido que, nos últimos anos, maior atenção tem sido dada à perda de florestas pelo desmatamento, à perda de biodiversidade e ao aumento de emissões de gases do efeito estufa (VIBRANS et al., 2012).

A grande área ocupada com reflorestamentos de pinus nos estados de Santa Catarina, Paraná e Rio Grande do Sul eleva a importância de estudos dos impactos e modificações que essa atividade causa no solo, especialmente com relação à distribuição das substâncias húmicas da matéria orgânica do solo (MOS). Esses estudos certamente possibilitam o melhor entendimento dos processos de humificação e estocagem de carbono orgânico no solo em decorrência da substituição de áreas naturais por plantios homogêneos de pinus.

O uso do solo tem estreita relação com a dinâmica da matéria orgânica e com o ciclo biogeoquímico dos elementos e sua modificação pode alterar a capacidade produtiva dos sistemas edafo-climáticos, especialmente nas condições de solos ácidos e intemperizados (MAFRA et al., 2008). Nos ambientes tropicais e subtropicais de ocorrência natural da mata atlântica e campos de altitude, há predominância de solos intemperizados, onde a matéria orgânica do solo tem papel fundamental para a sua fertilidade (MIRANDA; CANELLAS; NASCIMENTO, 2007). Em geral, a função mais importante da matéria orgânica é manter a reserva e fornecer nitrogênio e outros nutrientes necessários para o crescimento das plantas. Além disso, a MOS contribui decisivamente para a formação de agregados estáveis, proteção da superfície do solo, como substrato energético para a atividade da biota do solo, para a capacidade de troca de cátions, bem como na estocagem de carbono terrestre (MACHADO, 2001).

O reflorestamento com árvores exóticas, especialmente em áreas de baixa fertilidade natural ou degradadas, tem sido uma estratégia usada para aumentar a qualidade do solo, promover o sequestro de carbono e simultaneamente produzir um retorno econômico (DICK et al., 2011). O cultivo de florestas, principalmente nas regiões tropicais, tem sido apontado como meio eficiente no sequestro de $\mathrm{C}$ em razão da acumulação deste na madeira e aumento do estoque no solo (PULROLNIK et al., 2009). Dessa forma, há crescente interesse no estudo do comportamento dos solos quanto à sua capacidade de armazenar carbono e nutrientes, em resposta às diversas condições de manejo adotadas. A avaliação dessas mudanças auxiliaria a compreensão das alterações no ambiente advindas do reflorestamento, contribuindo para o planejamento do manejo florestal (MAFRA et al., 2008).

A matéria orgânica presente no solo e nos resíduos pode ser dividida em dois grandes compartimentos: sendo um deles composto pela fração não-humificada, e outro, o compartimento formado pelas substâncias humificadas (CANELLAS et al., 2001). Essas substâncias que integram a matéria orgânica humificada do solo são separadas em diferentes frações, de acordo com sua solubilidade. De modo geral, as frações humificadas são separadas em três categorias: a huminas (HUM) que representam os compostos mais estáveis, intimamente ligados aos minerais do solo, e por isso não são extraídas em meio alcalino; os ácidos fúlvicos (AF), que apresentam grande quantidade de grupamentos funcionais oxigenados e são solúveis tanto em meio alcalino, como ácido, e os ácidos húmicos (AH) que são insolúveis em meio fortemente ácido, pois, com a protonação dos grupamentos funcionais ocorre o colapso da estrutura e a precipitação das macromoléculas (CANELLAS et al., 2001).

Os ácidos fúlvicos são compostos de maior solubilidade por apresentar maior polaridade e menor tamanho molecular. São os principais responsáveis por mecanismos de transporte de cátions no solo. Os ácidos húmicos são os compostos mais estudados e apresentam pouca solubilidade na acidez normalmente encontrada em solos tropicais, sendo responsáveis pela maior parte da CTC de origem orgânica em camadas superficiais do solo. A humina, apesar de apresentar baixa reatividade, contribui para a agregação das 
partículas e, na maioria dos solos tropicais, representa a maior fração do C humificado do solo (BENITES; MADARI; MACHADO, 2003; BARRETO et al., 2008).

As relações entre as frações químicas da MOS são associadas à magnitude de processos onde, de acordo com Benites, Madari e Machado (2003), a relação AH/AF é associada à mobilidade do carbono no solo, enquanto a relação EA(elementos solúveis em álcali)/HUM é associada à iluviação de matéria orgânica. Em geral os solos mais arenosos apresentam maiores relações AH/AF indicando a perda seletiva da fração mais solúvel (AF). Basicamente, o comportamento das SH no perfil do solo depende da movimentação da solução no perfil e da sua solubilidade na solução.

Segundo Fontana et al. (2010) as informações obtidas a partir da análise da distribuição das frações húmicas podem contribuir para os estudos pedológicos, podendo ser utilizadas como atributo diagnóstico ou propriedade diferencial de classes. Sua utilização tem por base a análise da distribuição dessas frações ao longo do perfil de solo, sendo esta condicionada por sua mobilidade e também pela maior ou menor interação das frações com a matriz mineral. A maior mobilidade e, ou, estabilidade dessas frações influencia na diferenciação dos horizontes, com reflexos em suas propriedades físicas e químicas.

As consequências da substituição do ecossistema de campo natural por reflorestamentos de pinus sobre a matéria orgânica do solo ainda são pouco conhecidas nas condições do sul do Brasil, embora sejam de grande interesse tendo em vista a participação da matéria orgânica em inúmeros processos no solo (GUEDES, 2005). Os resultados de alguns estudos sobre os reflexos da mudança de uso do solo são em geral variáveis quanto à suas causas e magnitudes na quantidade e qualidade da MOS parecem depender do tipo de solo, idade da plantação, espécies florestais, localização geográfica e clima, entre outros fatores (ALMEIDA et al., 2012).

Os objetivos desse trabalho foram determinar os efeitos da substituição do campo natural por floresta homogênea de pinus nos teores e proporções de $\mathrm{C}$ das substâncias húmicas da MOS e a influência da idade do plantio de pinus nesses teores e proporções.

\section{MATERIAL E MÉTODOS}

O estudo foi realizado em áreas localizadas no município de Ponte Alta no planalto sul do estado de Santa Catarina, em altitude entre 950 a 1000 m acima do nível do mar. Segundo a classificação climática de Köppen, o clima local é do tipo $\mathrm{Cfb}$, mesotérmico úmido com verões amenos. A temperatura média anual está entre $14{ }^{\circ} \mathrm{C}$ e $16^{\circ} \mathrm{C}$ e a precipitação pluviométrica anual entre $1600 \mathrm{~mm}$ e $1900 \mathrm{~mm}$ (ALVARES et al., 2013).

Foram selecionadas quatro áreas para realização do experimento com o cuidado de obter similaridade de tipo e classificação de solo. Assim, o solo analisado foi classificado como Cambissolo Húmico distrófico. As áreas avaliadas foram: campo natural (CN) situado nas coordenadas $27^{\circ} 29^{\prime} 09,02$ ' S e 50 19'21,69'”, que originalmente foi floresta, mas encontrava-se em situação de campo pastejado por bovinos há cerca de 20 anos e que, além do pastejo recebe roçada anualmente; pinus com 5 anos (P05) situado nas coordenadas $27^{\circ} 29^{\prime} 05,43^{\prime \prime}$ S e $50^{\circ} 17^{\prime} 57,14^{\prime \prime} \mathrm{O}$; pinus com 16 anos (P16) situado nas coordenadas $27^{\circ} 24^{\prime} 53,64^{\prime \prime} \mathrm{S}$ e

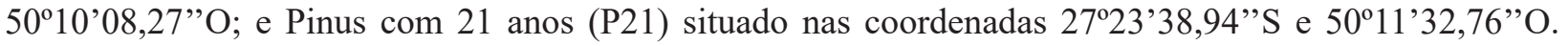
Todas as áreas com pinus se encontravam em segunda rotação, tendo o plantio anterior um ciclo de 28 anos. O plantio teve preparo por meio de ripagem com trator de esteira com haste de $40 \mathrm{~cm}$ de profundidade e conjunto de dois discos acoplados.

A amostragem de solo foi realizada com auxílio de um trado do tipo holandês, coletando-se em sete pontos amostrais dentro de cada área. Cada ponto amostral foi composto por sete subamostras dispostos num círculo com raio de $10 \mathrm{~m}$ com a primeira subamostra no centro. As profundidades amostradas foram de $0-5 \mathrm{~cm}, 5-10 \mathrm{~cm}, 10-20 \mathrm{~cm}, 20-30 \mathrm{~cm}$ e $30-40 \mathrm{~cm}$.

Foram determinados os teores de carbono nas três frações químicas da matéria orgânica do solo, ácidos fúlvicos, ácidos húmicos e humina. Para isto, utilizou-se a metodologia adaptada por Benites, Madari e Machado (2003), de fracionamento químico da MOS via solubilização em meio ácido/básico. A quantificação do carbono orgânico de cada fração foi realizada pela oxidação por bicromato em meio ácido e titulação com sulfato ferroso amoniacal. Em tubos falcon de $50 \mathrm{ml}$ foram pesados $2 \mathrm{~g}$ de solo e adicionados $10 \mathrm{ml}$ de solução $\mathrm{NaOH}$ 0,1 $\mathrm{Mol} \mathrm{L}^{-1}$. Agitou-se manualmente por alguns segundos e posteriormente deixou- 
se em repouso por $24 \mathrm{~h}$. Para a separação dos extratos, as amostras foram centrifugadas a 3500 RPM (2964 g) por 1 hora. Após a centrifugação retirou-se a alíquota sobrenadante com cuidado, para não perder o precipitado, e armazenou-se em copo plástico devidamente identificado. A seguir, adicionou-se mais $10 \mathrm{ml}$ de solução $\mathrm{NaOH} 0,1 \mathrm{Mol} \mathrm{L}^{-1}$ nas amostras e agitou-se manualmente até o desprendimento total do precipitado do fundo do tubo. Deixou-se então em repouso novamente por 1 hora e após as amostras estarem precipitadas, estas foram centrifugadas uma segunda vez e uma nova alíquota de sobrenadante foi adicionada à alíquota previamente reservada. Corrigiu-se o $\mathrm{pH}$ para $1 \pm 0,1$ com solução $\mathrm{H}_{2} \mathrm{SO}_{4}$ a $20 \%$ e deixou-se as amostras em repouso novamente por pelo menos $18 \mathrm{~h}$, visando a precipitação da fração não solúvel em solução ácida. Os precipitados restantes nos tubos falcon foram devidamente armazenados e representam a fração insolúvel da MOS, a humina. Este último repouso facilita a filtragem das amostras que caracteriza a separação das frações ácidos fúlvicos e húmicos. Os extratos foram ainda filtrados em filtro de fibra de celulose $0,45 \mu \mathrm{m}$, utilizando-se aparelho de filtragem em acrílico com conexão à bomba de vácuo para acelerar o processo, e posteriormente as alíquotas filtradas foram completadas com água destilada até $50 \mathrm{ml}$. Assim, ao final do procedimento, cada amostra gerou 3 alíquotas dispostas em tubos falcon, sendo um para cada fração das SH da MOS.

Para os ácidos húmicos e ácidos fúlvicos foram transferidos uma alíquota de 5,0 $\mathrm{ml}$ para tubos de digestão, tendo-se previamente diluído as amostras com excesso de $\mathrm{C}$, estimado pela coloração mais escura dos extratos. Concomitantemente, realizou-se o mesmo procedimento em 4 repetições para o branco da análise, utilizando-se 5,0 ml de água destilada. Adicionou-se $1,0 \mathrm{ml}$ de dicromato de potássio $\left(\mathrm{K}_{2} \mathrm{Cr}_{2} \mathrm{O}_{7}\right)$ $0,042 \mathrm{Mol} \mathrm{L}^{-1}$ e 5,0 $\mathrm{ml}$ de ácido sulfúrico $\left(\mathrm{H}_{2} \mathrm{SO}_{4}\right)$ concentrado em todas as amostras, incluindo os brancos. Os extratos foram então digeridos em bloco digestor à temperatura de $150{ }^{\circ} \mathrm{C}$ durante 30 minutos. No caso da fração humina, o precipitado foi totalmente transferido por lavagem, com jatos de água destilada, para os tubos de digestão que foram secos em estufa a $65^{\circ} \mathrm{C}$ antes da digestão.

A titulação do bicromato remanescente da digestão foi feita com a solução de sulfato ferroso amoniacal $\left(\mathrm{Fe}\left(\mathrm{NH}_{4}\right)_{2}\right)$ na concentração de $0,0125 \mathrm{Mol} \mathrm{L}^{-1}$ para as frações solúveis (AF e AH) e de 0,25 Mol $\mathrm{L}^{-1}$ para a fração insolúvel (HUM), utilizando-se de Ferroin $0,025 \mathrm{Mol} \mathrm{L}^{-1}$ como indicador.

Os resultados foram submetidos à análise de variância pelo procedimento PROC GLM do software SAS 9.2 com a comparação entre as médias pelo teste $t$ (Student) com nível de $5 \%$ de significância.

\section{RESULTADOS E DISCUSSÃO}

Os teores de C nas SH da matéria orgânica do solo variaram significativamente em função da situação de cultivo e profundidade do solo (Tabela 1). Notou-se que em relação ao campo natural, o plantio de Pinus na fase inicial de cultivo teve menores teores de $\mathrm{C}$ na fração humina e na soma das três frações. Porém, com a evolução da idade da floresta, observou-se a recuperação desses teores com incremento significativo em todas as frações entre as idades 16 anos e dessa para 21 anos. Almeida et al. (2012) avaliaram o impacto da introdução da monocultura de pinus nos estoques de carbono, também em Cambissolo de Lages (SC), em cada compartimento químico da MOS, e também obtiveram variações significativas mostrando que houve interação entre os ambientes e profundidades analisados. Avaliando a substituição de áreas de pastagem natural por plantios de pinus em áreas de Neossolo Litólico em Campos de Cima da Serra (RS), Dick et al. (2011) também encontraram diferenças significativas entre as situações de uso e entre camadas do solo.

A diminuição inicial, em Pinus de 5 anos, nos teores de carbono (C) (SOMA) pode ser explicada devido ao manejo prévio da área para introdução da floresta que favorece a oxidação microbiana da matéria orgânica. Além disso, existe o fato que nos primeiros anos da floresta a copa das árvores não cobre o solo totalmente e há menor deposição de serapilheira, o que não é suficiente para repor o $\mathrm{C}$ perdido como $\mathrm{CO}_{2}$. Assim, na fase inicial da floresta, o solo permanece por maior tempo exposto às chuvas e incidência solar direta. De outro lado, as acículas também possuem decomposição mais lenta em relação às gramíneas, apresentando reposição mais lenta do C na forma de SH devido ao maior teor de lignina da sua composição (WIESMEIER et al., 2009). Em experimento com povoamentos de eucalipto, pinus e vegetação natural no cerrado, Montero (2008) concluiu que a utilização de espécies de crescimento rápido mostrou-se útil no processo de sequestro de carbono, porém é necessário agir com cautela, pois podem ocorrer perdas do carbono original do solo em função das práticas empregadas no preparo do solo e manejo das áreas. 
TABELA 1: Teor de carbono orgânico (C) na camada 0-40 cm nas frações ácidos fúlvicos (AF), ácidos húmicos (AH) e humina (HUM) das substâncias húmicas do solo e somatório dessas três frações (SOMA) em quatro situações de uso em Cambissolo Húmico da região do Planalto Sul de Santa Catarina.

TABLE 1: Organic carbon (C) content on 0-40 cm soil layer in the fulvic acids (AF), humic acids (AH) and humin (HUM) of humic substances and sum of these three fractions (SOMA) on four situations of soil use in a Humic Dystrupept in southern Brazilian highlands.

\begin{tabular}{|c|c|c|c|c|}
\hline \multirow{2}{*}{ Situação de Cultivo } & $\mathrm{AF}$ & $\mathrm{AH}$ & HUM & SOMA (C) \\
\hline & \multicolumn{4}{|c|}{--------------------------------------- ${ }^{-1}$} \\
\hline Campo Natural & $3,4 \mathrm{c}$ & $6,2 \mathrm{c}$ & $7,9 \mathrm{c}$ & $17,5 \mathrm{c}$ \\
\hline Pinus 5 Anos & $3,6 \mathrm{c}$ & $5,4 \mathrm{c}$ & $6,5 \mathrm{~d}$ & $15,4 d$ \\
\hline Pinus 16 Anos & $4,4 \mathrm{~b}$ & $7,7 \mathrm{~b}$ & $10,7 \mathrm{~b}$ & $22,8 \mathrm{~b}$ \\
\hline Pinus 21 Anos & $5,3 \mathrm{a}$ & $13,7 \mathrm{a}$ & $15,3 \mathrm{a}$ & $34,3 \mathrm{a}$ \\
\hline
\end{tabular}

Em que: Letras iguais na coluna não diferem significativamente pelo teste " $\mathrm{t}$ " a 5\%.

Os teores médios de $\mathrm{C}$ recuperados nas três frações e na sua soma em todas as áreas evidenciaram maiores valores de acúmulo de carbono orgânico na camada superficial de 0 a $5 \mathrm{~cm}$ em todas as frações (Tabela 2). Em geral, o teor diminuiu com o aumento na profundidade até a camada de 20 a $30 \mathrm{~cm}$ e essa não apresentou diferenças significativas com a de 30 a $40 \mathrm{~cm}$. A distribuição de carbono orgânico, nos perfis dos solos, varia bastante ao nível global, observando-se em geral menores quantidades armazenadas na superfície dos solos tropicais do que nos solos florestais de latitudes maiores (OLIVEIRA, 2010).

O decréscimo nos teores com a profundidade era esperado, devido ao fato da deposição das folhas e ramos finos ocorrer na superfície do solo, sendo que na camada mais superficial também ocorre intensa ciclagem de raízes finas. A movimentação desse carbono para o interior do perfil é lenta, formando um gradiente a partir da superfície. Porém, observou-se um comportamento diferenciado com relação ao carbono na fração dos ácidos fúlvicos (AF) que apresentou teor semelhante ao longo do perfil a partir da camada 5 a $10 \mathrm{~cm}$. Isso se explica pela constituição química dessa fração que apresenta menor peso molecular dentre

TABELA 2: Teor de carbono orgânico em cinco camadas até $40 \mathrm{~cm}$ de profundidade do solo nas frações ácidos fúlvicos (AF), ácidos húmicos (AH) e humina (HUM) das substâncias húmicas do solo e somatório dessas três frações (SOMA) em quatro situações de uso em Cambissolo Húmico da região do Planalto Sul de Santa Catarina. Médias de áreas sob as quatro situações de uso: campo natural, plantios de pinus aos 5, 16 e 21 anos de idade.

TABLE 2: Organic carbon content in five layers up to $40 \mathrm{~cm}$ of soil depth in the fulvic acids (AF), humic acids (AH) and humin (HUM) of humic substances and sum of these three fractions (SOMA) on four situations of soil use in a Humic Dystrupept in southern Brazilian highlands. Average of four soil uses: natural grassland and pinus at the 5, 16 and 21 years old.

\begin{tabular}{ccccc}
\hline \multirow{2}{*}{ Camadas (cm) } & AF & AH & HUM & SOMA \\
\cline { 2 - 5 } & ----------- \\
\hline 0 a 5 & 4,7 a & $9,1 \mathrm{a}$ & $11,5 \mathrm{a}$ & $25,3 \mathrm{a}$ \\
5 a 10 & $4,1 \mathrm{~b}$ & $8,5 \mathrm{ab}$ & $11,1 \mathrm{ab}$ & $23,6 \mathrm{~b}$ \\
$10 \mathrm{a} 20$ & $3,9 \mathrm{~b}$ & $8,2 \mathrm{ab}$ & $10,5 \mathrm{~b}$ & $22,6 \mathrm{~b}$ \\
$20 \mathrm{a} 30$ & $4,0 \mathrm{~b}$ & $7,6 \mathrm{~b}$ & $9,2 \mathrm{c}$ & $20,7 \mathrm{c}$ \\
$30 \mathrm{a} 40$ & $4,1 \mathrm{~b}$ & $7,9 \mathrm{~b}$ & $8,2 \mathrm{c}$ & $20,2 \mathrm{c}$ \\
\hline
\end{tabular}

Em que: Letras iguais na coluna não diferem significativamente pelo teste " $\mathrm{t}$ " a $5 \%$. 
as três frações, sendo então mais facilmente dispersa ou solúvel na solução do solo e movimentada pelo deslocamento desta no perfil do solo. Além disso, essa fração também é composta por maior quantidade de grupamentos carboxílicos apresentando maiores teores de oxigênio e menores de carbono, o que pode representar possibilidade maior de dispersão em água, correspondendo a maior suscetibilidade para se movimentar com a percolação de água no perfil do solo.

Miranda, Canellas e Nascimento (2007) observaram que frações orgânicas mais solúveis, como $\mathrm{AF}$, apresentam, em razão do seu elevado conteúdo de grupamentos funcionais polares, alta capacidade de solvatação, sendo mais suscetíveis ao arraste pela água de percolação do solo do que frações precipitadas como AH e HUM.

Os compostos integrantes dessas últimas frações, por constituírem moléculas com menor número de grupamentos carboxílicos e maior de grupamentos nitrogenados, os átomos de carbono possuem uma aproximação com ligações mais fortes entre si, favorecendo maior peso molecular, o que os tornam mais estáveis, tendo também maior tempo de permanência no solo.

$\mathrm{Na}$ camada superficial ( 0 a $5 \mathrm{~cm}$ ) a área de pinus com mais idade (P21) apresentou os maiores teores em todas as frações químicas, seguido pela área de pinus com 16 anos (P16), pinus com 5 anos (P05) e a de campo natural (CN) (Figura 1). Nessa camada, as últimas três áreas em geral apresentaram teores de C orgânico semelhante nas frações das SH individualmente. Porém, considerando o teor total de $\mathrm{C}$ das $\mathrm{SH}$ a área de $\mathrm{CN}$ apresentou os menores teores, o que se explica pelo manejo existente nessa área que vem sendo submetida ao pastejo intensivo por bovinos, o que resultou em baixa produtividade fotossintética, com menor deposição de resíduos orgânicos no solo.

O teor de carbono contido na soma das três frações de SH na área de P21 chegou a $38,3 \mathrm{~g} \mathrm{~kg}^{-1}$ distribuído em $6,5 \mathrm{~g} \mathrm{~kg}^{-1} ; 14,1 \mathrm{~g} \mathrm{~kg}^{-1}$ e 17,7 $\mathrm{g} \mathrm{kg}^{-1}$ para os ácidos fúlvicos, húmicos e humina, respectivamente, na camada mais superficial. $\mathrm{O}$ pinus tem desenvolvimento fisiológico relativamente rápido, com alta produção de massa vegetal e deposição de serapilheira, principalmente acículas, com alto teor de carbono na sua estrutura, mostrando alta capacidade de sequestro de carbono da atmosfera, com parte expressiva sendo acumulada no solo. Assim, o solo sob o povoamento de pinus mais desenvolvido e maduro evidenciou expressivo aumento no teor de carbono, que pode ser atribuído à intensa ciclagem de raízes finas no interior das camadas superficiais do solo e pela deposição das grandes quantidades de acículas produzidas pelas árvores e depositadas na superfície.

Abrão et al. (2015) também observaram alterações significativas no teor de carbono orgânico total em Cambissolo Húmico após a substituição de campo natural por plantios homogêneos de pinus, com diminuição nas áreas de primeira rotação. Porém o teor originalmente encontrado no campo natural foi recuperado na segunda rotação de plantio de pinus, chegando a valores até um pouco maiores do que os observados na vegetação natural. Já, Almeida et al. (2012) observaram que o estoque de carbono na camada de 0 a $5 \mathrm{~cm}$ foi maior em solo sob o reflorestamento de pinus aos 14 anos do que aos 10 anos de idade e do que sob pastagem natural, porém nas camadas mais profundas nenhuma diferença foi observada entre essas situações de uso.

Em experimento realizado por Guedes (2005) em Campo Belo do Sul, SC, também foram observadas variações na quantidade de carbono orgânico total entre diferentes situações de uso que incluíram campo natural, pinus de 12 anos, pinus de 20 anos, floresta de araucária plantada de 18 anos e mata nativa. Os teores de carbono variaram de $23 \mathrm{~g} \mathrm{~kg}^{-1}$ a $56 \mathrm{~g} \mathrm{~kg}^{-1}$ com efeito significativo das situações de uso e da profundidade, concentrando-se os maiores teores na camada superficial de 0 a $5 \mathrm{~cm}$, corroborando com os resultados do presente estudo. Na média das profundidades, os autores observaram que o solo sob pinus com 20 anos de idade teve maior teor de carbono em relação aos demais tratamentos, sendo seguido pelo campo nativo e pinus com 12 anos de idade. Em outro estudo realizado por Vargas (2012) no município de Otacílio Costa, SC, em solo Cambissolo Húmico o autor observou comportamento semelhante ao do atual estudo, em relação à distribuição das frações químicas das SH com a profundidade do solo e também constatou aumento do teor de carbono nos plantios de pinus de terceira rotação em relação aos de primeira.

Nas camadas sub-superficiais, de 5 a $10 \mathrm{~cm}$ e de 10 a $20 \mathrm{~cm}$, o teor de $\mathrm{C}$ das frações de $\mathrm{SH}$ do solo no CN passou a superar o do solo sob P05 e equivaleu estatisticamente ao P16. Este comportamento foi associado ao corte raso realizado na colheita da rotação anterior e à provável ocorrência de menor densidade e consequente ciclagem de raízes finas de pinus nessas camadas inferiores. Além disso, houve revolvimento 


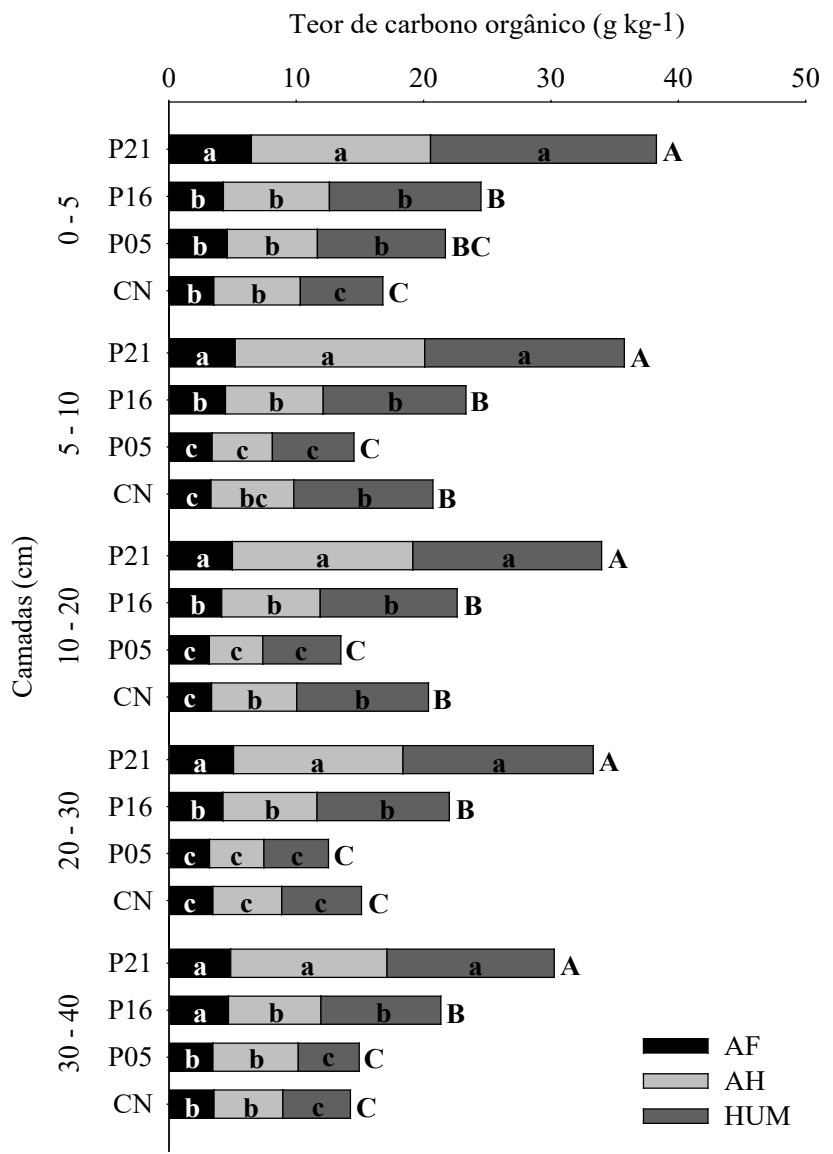

FIGURA 1: Distribuição dos teores de carbono orgânico $\left(\mathrm{g} \mathrm{kg}^{-1}\right)$ nas substâncias húmicas ácidos fúlvicos (AF), ácidos húmicos (AH) e humina (HUM), em áreas de Campo Natural (CN), Pinus 5 anos (P05), Pinus 16 anos (P16) e Pinus 21 anos (P21) em cinco camadas até a profundidade de $40 \mathrm{~cm}$ de Cambissolo Húmico. Letras minúsculas comparam teores das frações e maiúsculas os teores totais das substâncias húmicas entre as áreas dentro de cada camada a 5\% de significância.

FIGURE 1: Distribution of organic carbon content $\left(\mathrm{g} \mathrm{kg}^{-1}\right)$ in the humic substances, fulvic acids (AF), humic acids (AH), and humin (HUM), on native grassland (CN), five-year old Pinus (P05), sixteen-year old Pinus (P16), and twenty-one-year old Pinus (P21) areas, in five layers until depth of $40 \mathrm{~cm}$ in a Humic Dystrupept. Small letters compare carbon levels of the fractions and capital letters compare total levels of humic substances between areas inside every layer with $5 \%$ of significance.

do solo no processo de limpeza da área e estabelecimento das mudas da nova rotação, resultando em remoção pela raspagem da retirada de ramos da superfície do solo e também perdas de $\mathrm{C}$ para a atmosfera na forma de $\mathrm{CO}_{2}$, pelo estímulo à decomposição microbiana. Essas perdas de $\mathrm{C}$ demandam tempo para sua recuperação, o que foi evidenciado pelo maior teor observado nos plantios de pinus aos $16 \mathrm{e}$, principalmente, 21 anos de idade, embora nesse também tenha se observado valores decrescentes com a profundidade.

Em contraste ao presente trabalho, Tomasi, Inda e Dick (2012) analisando as SH em Latossolo Vermelho no estado do RS, em camadas até a profundidade de $30 \mathrm{~cm}$, encontraram teores maiores de carbono na área de $\mathrm{CN}$ em relação a uma área de pinus com 18 anos, em todas as camadas analisadas. Entretanto, nesse estudo a área de $\mathrm{CN}$ caracterizou uma condição de transição entre vegetação rasteira e arbustiva, tendo grande aporte de resíduos de raízes e de excedentes da pastagem aliado a restrições da degradação microbiana devida ao clima mais frio. Ainda, deve-se considerar que a área de pinus do estudo 
provavelmente encontrava-se em primeira rotação, onde, conforme observado acima, o teor de C orgânico do solo tende a ser menor do que nas rotações seguintes.

Nas camadas mais profundas, de 20 a $30 \mathrm{~cm}$ e de 30 a $40 \mathrm{~cm}$, a soma dos teores de C das três frações das áreas com CN e P05 foram semelhantes e mostraram ordem crescente nas áreas de P16 e P21. A área de P21 obteve os maiores teores de carbono nas SH como observado acima, o que se atribuiu ao maior aporte de material vegetal depositado em serapilheira, principalmente acículas, que possuem maior resistência para sua decomposição, além do maior volume e respectiva ciclagem de raízes, que também possuem grande potencial de formação de substâncias húmicas a partir da sua decomposição.

Os minerais da fração argila contribuem na proteção e consequente estabilização da matéria orgânica no solo (EBELING et al., 2011), o que também pode ter influenciado nos teores e estoques de carbono nas áreas avaliadas. Os teores de argila dos solos das áreas avaliadas no presente trabalho foram analisados em trabalho anterior por Fachini (2012), o qual observou menor teor de areia no pinus com 16 anos e maior teor de argila no pinus com 21 anos, entretanto, observou também que em geral não houve diferença estatística do teor de argila entre as camadas.

Na Figura 2 são apresentadas as proporções das frações húmicas da matéria orgânica de cada área avaliada. Em relação ao COT do solo, o compartimento constituído por maior teor de carbono foi o das SH que na soma de $\mathrm{AF}, \mathrm{AH}$ e HUM representou a maior parte do C contido na matéria orgânica morta do solo. Isso se explica por essas substâncias constituírem as formas mais estáveis que podem se acumular no solo. Esses resultados também evidenciaram que os teores de carbono das SH foram influenciados pelo uso do solo.

Na Figura 2-A, onde estão representados apenas os teores totais de C das $\mathrm{SH}$, considerando-se a média ponderada da camada $0-40 \mathrm{~cm}$ nas diferentes áreas, podem-se observar nitidamente as diferenças entre as áreas avaliadas, com o aumento conforme a idade da floresta. Já, na Figura 2-B, encontram-se as proporções que cada fração representa no COT. Observou-se que as SH contém entre $80 \%$ e $90 \%$ do COT e, dentro dessas, a fração humina representa a maior porção do COT da matéria orgânica do solo, sendo responsável por $36,9 \%, 37,1 \%, 39,6 \%$ e 37,5 \% nas áreas de campo natural, pinus com 5, 16 e 21 anos,

(A)

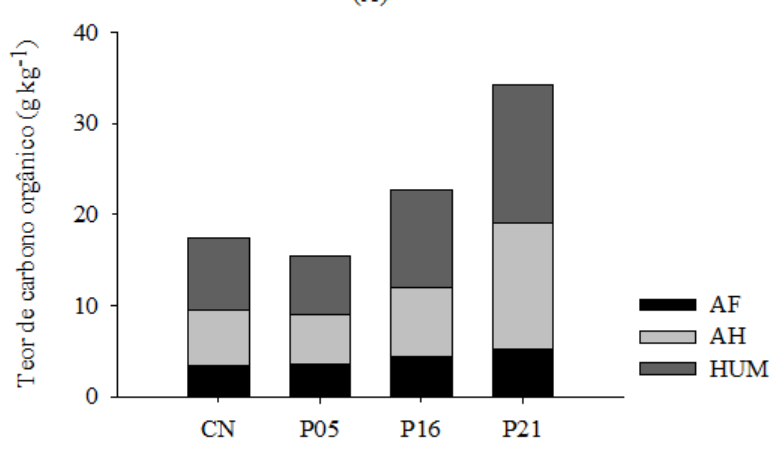

(B)

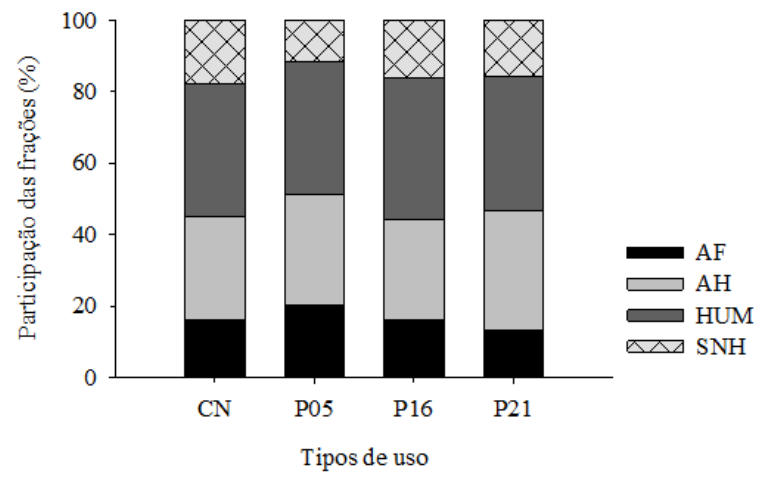

FIGURA 2: Teores de carbono orgânico nas frações das substâncias húmicas (SH): ácidos fúlvicos (AF), ácidos húmicos ( $\mathrm{AH}$ ), humina (HUM) e substâncias não-húmicas (SNH) em Cambissolo Húmico de áreas sob uso com Campo Natural (CN), Pinus 5 anos (P05), Pinus 16 anos (P16) e Pinus 21 anos (P21) (gráfico A) e proporções dessas frações com relação ao carbono orgânico total (COT) do solo (gráfico B). Valores representam a média ponderada dos teores observados nas camadas de 0-5, 5-10, 10-20, 20-30 e 30-40 cm de profundidade do solo.

FIGURE 2: Organic Carbon content on fractions of the humic substances (SH): fulvic acids (AF), humic acids (AH), humin (HUM), and non-humic substances (SNH) on Humic Cambisol from areas under native grassland (CN), five-year old Pinus (P05), sixteen-year old Pinus (P16), and twenty-one-year old Pinus (P21) (Graph A) and proportion of these chemical fractions related to total organic carbon (TOC) (Graph B). Values represent weighted average of the content on $0-5,5-10,10-20,20-30$, and $30-40 \mathrm{~cm}$ of soil depth. 
respectivamente, corroborando com Barreto et al. (2008), que também encontraram os maiores teores de carbono nessa fração considerada mais estável na camada superficial do solo.

Entretanto, em trabalho realizado por Miranda, Canellas e Nascimento (2007), o fracionamento da MOS indicou que as SH representaram menos de $50 \%$ do $\mathrm{C}$ total prontamente oxidável dos solos em estudo, refletindo características de húmus pouco evoluído. Nesse caso, a matéria orgânica do solo se mostrou constituída principalmente pela fração leve, o que foi atribuído pelos autores à baixa atividade biológica causada pela forte restrição de fertilidade observada no solo. Com relação à distribuição das frações das SH, a maior parte do C foi encontrado na fração humina, que representou entre 21 e $29 \%$ e 17 e $27 \%$ do $\mathrm{C}$ total nas profundidades de $0-10$ e $10-20 \mathrm{~cm}$, respectivamente.

A relação entre os teores de ácidos fúlvicos e ácidos húmicos e a relação entre as $\mathrm{SH}$ solúveis $(\mathrm{AF}+\mathrm{AH})$ pela fração humina são índices utilizados para avaliar o processo de humificação e representam o nível de evolução da matéria orgânica do solo. Observou-se, conforme descrito na Tabela 3, que as relações $\mathrm{AH} / \mathrm{AF}$ apresentaram valores acima de 1, indicando que as áreas estudadas caracterizam situações de estado transformado da matéria orgânica do solo pelo processo de humificação. Observou-se que o valor dessa relação no pinus com 21 anos foi superior aos demais usos nas camadas de 5 a $30 \mathrm{~cm}$, caracterizando o aumento do estágio de estabilização da matéria orgânica do solo com o avanço da idade da floresta.

As relações entre as substâncias solúveis e a humina também foram em geral maiores do que 1, observando-se que, mesmo com a fração humificada mais estável estar em maiores teores individualmente do que as formas mais lábeis, essa ainda não supera a soma das frações solúveis. Sendo assim, mesmo aumentando o aporte de carbono com a evolução da idade e desenvolvimento das florestas de pinus, o $\mathrm{C}$ orgânico das áreas estudadas não se encontra majoritariamente nas formas mais estáveis da matéria orgânica. Observa-se assim, que nesse solo e situações de cultivo o tempo necessário para a estabilização da MOS é longo, superando o período de duas décadas. Os maiores teores de carbono nas frações lábeis podem também, em parte, serem explicados pela alta taxa de deposição da serapilheira e de renovação de raízes finas e sua consequente decomposição aumentando o teor de matéria fresca em estágios iniciais de

TABELA 3: Relações de C contido nas substâncias húmicas entre ácidos húmicos e ácidos fúlvicos (AH/ $\mathrm{AF})$ e entre elementos solúveis em álcali e humina ( $\mathrm{AF}+\mathrm{AH}) / \mathrm{HUM}$, em camadas até $40 \mathrm{~cm}$ de profundidade de Cambissolo Húmico sob situações de uso com campo natural (CN), Pinus de 5 anos (P05), Pinus de 16 anos (P16) e Pinus de 21 anos (P21).

TABLE 3: Relations of content of $\mathrm{C}$ between humic substances, $\mathrm{AH}$ (humic acids)/AF (fulvic acids) and $\mathrm{EA}($ alcali soluble elements $=\mathrm{AF}+\mathrm{AH}) / \mathrm{HUM}$ (humin), by layer on Humic Dystrupept in every kind of soil use (CN - native field; P05 - 5-year old Pinus; P16 - 16-year old Pinus; P21 - 21year old Pinus).

\begin{tabular}{ccccc}
\hline \multirow{2}{*}{ Camadas $(\mathrm{cm})$} & CN & P05 & P16 & P21 \\
\cline { 2 - 5 } & \multicolumn{5}{c}{ AH/AF } \\
\hline 0 a 5 & $1,9 \mathrm{ab}$ & $1,5 \mathrm{~b}$ & $1,9 \mathrm{ab}$ & $2,3 \mathrm{a}$ \\
$5 \mathrm{a} 10$ & $2,0 \mathrm{~b}$ & $1,4 \mathrm{c}$ & $1,7 \mathrm{bc}$ & $2,9 \mathrm{a}$ \\
$10 \mathrm{a} 20$ & $2,1 \mathrm{~b}$ & $1,4 \mathrm{c}$ & $1,9 \mathrm{~b}$ & $2,9 \mathrm{a}$ \\
$20 \mathrm{a} 30$ & $1,6 \mathrm{bc}$ & $1,3 \mathrm{c}$ & $1,8 \mathrm{~b}$ & $2,7 \mathrm{a}$ \\
$30 \mathrm{a} 40$ & $1,5 \mathrm{~b}$ & $2,0 \mathrm{ab}$ & $1,6 \mathrm{~b}$ & $2,5 \mathrm{a}$ \\
\hline \multicolumn{5}{c}{ EA/HUM } \\
\hline a 5 & $2,2 \mathrm{a}$ & $1,1 \mathrm{~b}$ & $1,2 \mathrm{~b}$ \\
5 a 10 & $1,0 \mathrm{~b}$ & $1,1 \mathrm{ab}$ & $1,3 \mathrm{a}$ \\
$10 \mathrm{a} 20$ & $1,0 \mathrm{~b}$ & $1,2 \mathrm{~b}$ & $1,1 \mathrm{ab}$ & $1,3 \mathrm{a}$ \\
$20 \mathrm{a} 30$ & $1,6 \mathrm{a}$ & $1,3 \mathrm{a}$ & $1,1 \mathrm{~b}$ & $1,2 \mathrm{ab}$ \\
$30 \mathrm{a} 40$ & $1,8 \mathrm{ab}$ & $1,3 \mathrm{a}$ & $1,3 \mathrm{c}$ & $1,3 \mathrm{bc}$ \\
\hline
\end{tabular}

Em que: Letras iguais na linha não diferem significativamente pelo teste t a $5 \%$. 
decomposição, especialmente na camada mais superficial.

Fontana et al. (2001) também encontraram valores da relação AH/AF superiores a 1, corroborando com os resultados do presente estudo, embora em áreas de floresta secundária e pastagem na cidade de Campos dos Goytacazes (RJ) com solos classificados como Latossolo Amarelo e Argissolo Amarelo. Porém, Barreto et al. (2008) encontraram valores abaixo de 1 para esta relação em todas as três áreas analisadas, caracterizadas por mata atlântica, plantio de cacau e pastagem natural de um Latossolo Vermelho-Amarelo em região de clima quente e úmido, que proporcionou altos teores de ácidos fúlvicos e baixos teores de ácidos húmicos.

De acordo com Canellas et al. (2002) a relação AH/AF representa uma importante característica da matéria orgânica e de sua estabilidade, inclusive como um indicador da qualidade do solo, sendo que em solos ácidos, o desenvolvimento de fungos é favorecido e promove a degradação de lignina dos polifenóis, que dão origem as substâncias menos polimerizadas. O baixo conteúdo de bases trocáveis no solo pode também diminuir a intensidade do processo de humificação, condensação e síntese das SH.

\section{CONCLUSÕES}

A substituição de pastagem natural por plantios homogêneos de pinus pode aumentar o teor e a estabilização do carbono orgânico do solo, mostrando alto potencial de sequestro deste elemento da atmosfera e seu armazenamento no compartimento solo.

Quanto maior foi o tempo de uso pelo Pinus (com excessão a área de Pinus com 5 anos), em substituição ao Campo Natural, maior foi o acúmulo de carbono orgânico em substâncias húmicas no solo.

O teor de carbono orgânico do solo foi maior na fração humina em relação às frações ácidos húmicos e ácidos fúlvicos em todas as camadas e áreas analisadas, entretanto, a soma das substâncias solúveis foi em geral maior do que as não solúveis, sendo esta relação entre 0,95 e 2,22, o que sugere que a matéria orgânica não está estabilizada.

\section{REFERÊNCIAS}

ABRÃO, S. F. et al. Alterações químicas de um Cambissolo Húmico causadas por florestamento com Pinus taeda em área de campo natural. Floresta, Curitiba, v. 45, n. 3, p. 455-464, 2015.

ALMEIDA, H. C. et al. Distribution of chemical compartments of soil organic matter and C stocks of a cambisol from south Brazil as affected by Pinus afforestation. Química Nova, São Paulo, v. 35, n. 7, 2012. ALVARES, C. A. et al. Köppen's climate classification map for Brazil. Meteorologische Zeitschrift, Berlin, v. 22, n. 6, p. 711-728, 2013.

BARRETO, A. C. et al. Fracionamento químico e físico do carbono orgânico total em um solo de mata submetido a diferentes usos. Revista Brasileira de Ciência do Solo, Viçosa, MG, v. 32, n. 4, 2008.

BENITES, V. M.; MADARI, B.; MACHADO, P. L. O. A. Extração e fracionamento quantitativo de substâncias húmicas do solo: um procedimento simplificado de baixo custo. Rio de Janeiro: Ministério da Agricultura, Pecuária e Abastecimento, 2003.7 p. (Comunicado Técnico).

CANELLAS, L. P. et al. Distribuição da matéria orgânica e características de ácidos húmicos em solos com adição de resíduos de origem urbana. Pesquisa agropecuária brasileira, Brasília, v. 36, n. 12, 2001.

CANELLAS, L. P. et al. Distribution of the humified fractions and characteristics of the humic acids of an ultisol under cultivation of eucalyptus and sugar cane. Terra, Chapingo, v. 20, p. 371-381, 2002.

DICK, D. P. et al. Pinus afforestation in South Brazilian highlands: soil chemical attributes and organic matter composition. Sciencia Agricola, Piracicaba, v. 68, n. 2, 2011.

EBELING, A. G. et al. Substâncias húmicas e relação com atributos edáficos. Bragantia, Campinas, v. 70, n. 1, 2011.

FACHINI, L. Frações e estoques de carbono orgânico em solo do Planalto Catarinense cultivado com Pinus. 2012. 51 f. Dissertação (Mestrado) - Centro de Ciências Agroveterinárias, Universidade do Estado de Santa Catarina, Florianópolis, 2012.

FONTANA, A. et al. Matéria orgânica em solos e tabuleiros na Região Norte Fluminense-RJ. Floresta e Ambiente, Rio de Janeiro, v. 8, p. 114-119, 2001. 
FONTANA, A. et al. Quantificação e utilização das frações húmicas como característica diferencial em horizontes diagnósticos de solos Brasileiros. Revista Brasileira de Ciência do Solo, Viçosa, MG, v. 34, n. 4, 2010 .

GUEDES, S. F. F. Carbono orgânico e atributos químicos do solo em áreas florestais no Planalto dos Campos Gerais, SC. 2005. 58 f. Dissertação (Mestrado) - Centro de Ciências Agroveterinárias, Universidade do Estado de Santa Catarina, Florianópolis, 2005.

MACHADO, P. L. O. A. Manejo da matéria orgânica de solos tropicais: abrangência e limitações. Rio de Janeiro: Embrapa Solos, 2001. 25 p.

MAFRA, Á. L. et al. Carbono orgânico e atributos químicos do solo em áreas florestais. Revista Árvore, Viçosa, MG, v. 32, n. 2, 2008.

MIRANDA, C. C.; CANELLAS, L. P.; NASCIMENTO, M. T. Caracterização da matéria orgânica do solo em fragmentos de mata atlântica e em plantios abandonados de eucalipto. Revista Brasileira de Ciência do Solo, Viçosa, MG, v. 31, n. 5, 2007.

MONTERO, L. L. Carbono em solos de cerrado: efeitos do uso florestal. 2008. 117 f. Tese (Doutorado) - Universidade de São Paulo, São Paulo, 2008.

OLIVEIRA, L. P. Carbono e nutrientes no solo e na serapilheira em Floresta Ombrófila Mista Montana e plantio de Pinus elliottii Engelm. 2010. 65 f. Dissertação (Mestrado) - Setor de Ciências Agrárias e Ambientais, Universidade Estadual do Centro-Oeste, Curitiba, 2010.

PULROLNIK, K. et al. Estoques de carbono e nitrogênio em frações lábeis e estáveis da matéria orgânica de solos sob eucalipto, pastagem e cerrado no Vale do Jequitinhonha - MG. Revista Brasileira de Ciência do Solo, Viçosa, MG, v. 33, n. 5, 2009.

RUDDIMAN, W. F. How did humans first alter global climate? Scientific American, Canadá, v. 292, p. 34-41, 2005.

TOMASI, C. A.; INDA, A. V.; DICK, D. P. Substâncias húmicas em Latossolo subtropical de altitude sob usos e manejos distintos. Ciência Rural, Santa Maria, v. 42, n. 12, 2012.

VARGAS, C. O. Formas de carbono e macronutrientes do solo em florestas de Pinus em primeira e terceira rotação no planalto sul catarinense. 2012. 103 f. Tese (Doutorado) - Centro de Ciências Agroveterinárias, Universidade do Estado de Santa Catarina, Florianópolis, 2012.

VIBRANS, A. C. et al. Inventário florístico florestal de Santa Catarina: diversidade e conservação dos remanescentes florestais. Blumenau: Edifurb, 2012. 244 p.

WIESMEIER, M. et al. Depletion of soil organic carbon and nitrogen under Pinus taeda plantations in Southern Brazilian grasslands (Campos). European Journal of Soil Science, Oxford, v. 60, n. 3, p. 311-487, 2009. 